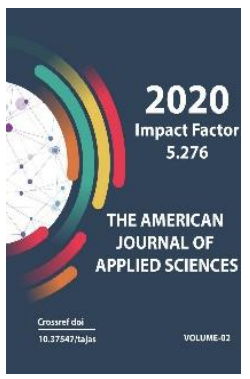

\title{
Practices To Fight Against Drugs In International Experience And Its Features
}

Mukhiddin Tursunmuratov

Researcher, Uzbekistan State World Languages University, Uzbekistan

Journal Website:

http://usajournalshub.c

om/index,php/tajas

Copyright: Original content from this work may be used under the terms of the creative commons attributes 4.0 licence.

\section{ABSTRACT}

This article examines the practice of combating drugs and its specific features in the world experience, which is one of the most pressing issues today. In particular, it focuses on drug addicts, their monitoring and related crime. The activities of the heroin and cocaine markets in the countries of the world (USA, Western Europe, Russia) have been studied through clear statistical facts.

\section{KEYWORDS}

Fight against drugs, countries of the world, world experience, drug consumption, proliferation, illegal business, crime, drug development.

\section{INTRODUCTION}

In 2010, international experts estimated that about 230 million people, or 5 percent of the world's adult population (15 to 64 years old), had used illicit drugs at least once. Heroin, cocaine, and other drugs kill about 0.2 million people every year, destroy families, and cause thousands of deaths. Illicit drugs undermine socio-economic development and contribute to crime, instability, insecurity and the spread of HIV. Globally, drug use remains stable, but continues to grow in developing countries [1]. 
Sociologist Ivanov V.P. (2008) noted that "in 2005, the share of the global pharmaceutical market at the production level was estimated at $\$ 13$ billion, at the wholesale level (including deductions) at $\$ 94$ billion, and at the retail level (2008), on the basis of retail prices and considering confiscations and other losses 322 billion US dollars. Thus, the proliferation of drugs has a global character and is associated with organized crime, posing a real and growing threat to the entire human civilization.

To cite the findings of international experts published in the International Drug Report (2010), "there is a direct link between drugs and crime and violence. Drug cartels weaken the government and disrupt legitimate business. Proceeds from drug trafficking are used to fund some bloody conflicts. The financial loss is enormous. Large sums of money are being spent to strengthen the police, the judiciary and drug treatment and rehabilitation programs. Social spending is equally astonishing: street crime, gang warfare, fear, urban degradation, and ruined lives.

It should be noted that at the end of the twentieth century there was a new phenomenon in the fight against drug trafficking and addiction [2]. The international community, under the auspices of the United Nations, annually discusses the global drug situation and publishes the World Drug Report (2000-2013) through the United Nations Office on Drugs and Crime (UNODC), which provides a detailed analysis of international drug structures and the dynamics of the drug market. trends are identified and monitoring programs are proposed. Drugs, as well as programs to expand research and a deeply grounded approach to the problem, have created an integrated system of multilateral drug control. The legal basis of this system is the international conventions in the field of drugs - the Single Convention on Narcotic
Drugs (1961), the Convention on Psychotropic Substances (1971) and the United Nations Convention against Illicit Traffic in Narcotic Drugs and Psychotropic Substances (1988). (UN. Global Drug Reports (2000, 2004, 2005, 2006, 2008, 2009) [3].

One of the important aggravating factors in the development of drug addiction is the decline in drug prices, especially in Europe. The fall in drug prices will have catastrophic consequences in the coming years as people in the 'risk group' consume more drugs. In the dissertation research, political scientist Kirsanov noted that "there is no clear data on drug prices on the streets, they vary from country to country (e.g. in Portugal 1 gram of marijuana costs 2.3 euros, in Norway 12 euros; in Turkey $1 \mathrm{~g}$ of heroin costs 12 euros, in Sweden it costs 141 euros. However, the facts show that medicines are much cheaper today than they were 20-25 years ago. Today, the price of heroin in Europe has dropped by 45 percent and marijuana by 22 percent. "Illegal business" has a negative impact on socioeconomic development, both in individual countries and around the world, and creates a breeding ground for crime and instability. According to international and national experts and statistics published in the International Narcotics Report (2018), drug abuse on a global scale is multifaceted: in recent years, drug and psychotropic substance use has stabilized in economically developed countries in Europe and America. At the same time, drug use in developing countries, including drug and psychotropic substance use, is on the rise.

In terms of the scale of the drug problem and the prognosis of drug addiction, the assessment of the resources needed to implement anti-drug measures in countries, the problems of drug users [4].

Nearly 27 million people worldwide are classified as problem drug users, or $0.6 \%$ of the world's adult population. The definition of 
"drug users" is not legally defined. Drug users in countries are those who regularly consume and are addicted to drugs. This group includes all those who inject drugs. Since the end of the twentieth century, the following trend has been observed - with the increase in the number of illicit drug users, from 2004-2005, there has been a somewhat stabilizing trend among problem drug users [5].

\section{MATERIALS AND METHODS}

According to the latest data, the number of injecting drug users, including those living with HIV, was lower than expected in 2011: experts estimate that 14 million people between the ages of 15 and 64 are injecting drugs. 1.6 million injecting drug users are infected with HIV. These figures show that the number of injecting drug users has decreased by 12 percent since 2008 and the number of people injecting drugs living with HIV has decreased by 46 percent [6].

To assess the specific characteristics of countries such as drug trafficking, illicit transportation and non-medical consumption, in particular NS and PV. profile by age and sex, analysis of the literature in this area was conducted. At least half of high school graduates in the United States are familiar with drugs (Brook J., 1999; D.B. Clark, 2005). A survey of the population in the United States shows that drug and alcohol use among American school children begins at age 10 and peaks at age 14-15 [7].

Another such study was conducted by the University of Michigan Institute for Social Research (Ann Arbor). According to him, Lloyd Johnston, Geraral Bachman and Patrick O'Malley have been working on the "Monitoring the Future" project for the past 25 years. The Monitoring the Future Study, which has surveyed 15.5 thousand graduates of public and private schools in the United States each year since 1975, found that 41 percent (in 2018) experienced drug use at least once in each of these surveys, $65.5 \%$ of final (11-12) 4th grade students (in 2001). Apparently, these are very reliable figures (the differences between American measurements over time do not exceed 3-4\%), although they are significantly higher than our domestic figures, comparable to them. The "Future Observation" data, conducted by U.S. researchers, confirms that drastic changes to addiction are unlikely. The level of "illicit drug use" reported by school graduates was initially found to be a gradual increase (2-3\% per year) in the number of people with at least one experience of drug use (excluding alcohol and tobacco products) each year (55\% in 1975) up to $65.5 \%$ in 1981 . After that, the results of annual measurements show that the level of addiction in American school children began to decline steadily for almost a decade, and by 1992, the lowest level of observation had reached $40.7 \%$. This year saw not only a minimum level of the total number of people using any illegal drugs, but also the lowest level of those who used them in the last 30 days before the survey. Among American school graduates in 1992, the number of such "real consumers" was only $14.4 \%$, which is almost three times less than the total number of those who have used drugs at least once. This is if we focus on the fact that our daily and active consumption ratios are close enough to our internal ratios [8].

However, it was not possible to consolidate the dubious achievements of American society in the fight against drugs in the future - a new slow but steady growth began with the overall participation of American school graduates. Annual growth of no more than 2$3 \%$ in the spring of 1997, the number of people with at least one experience of drug use reached $54.3 \%$, increased by almost $14 \%$ in six years. The number of current consumers has increased significantly, reaching $26.2 \%$ in 1997 , almost twice as many as in 1992. By 1999, the 
level of familiarity with drugs had changed slightly, reaching $54.7 \%$ in 1999 [9].

In subsequent years, it was very slow (0.1\% to $0.9 \%$ per year), but nonetheless, this level began to decline. Finally, in 2003, the decline was $2 \%$ and total participation was $51.1 \%$. The change in the number of active consumers was observed in almost the same trend: after the peak in 1997, a slow decline of about $1 \%$ per year was observed, in 2003 this figure was $24.1 \%$ of all school graduates (Monitoring the Future Release from Dec. 19, 2003). It should be noted that the ratio of casual and active consumption among American high school students has changed over the past decade: since 1994, it has grown from about 3:1 to about 2:1.

For example, in Europe, Finland, 10 percent of the adult population has tried drugs at least once in their lives, while in Denmark and the UK, the proportion of these individuals reaches 25 and 30 percent, respectively. In general, in Europe this figure is around 20\% (Belgium, Germany, Spain, Ireland and the Netherlands). Consumption rates among young people remain almost twice as high as among the older generation. For example, about 15 percent of young people in Finland and Sweden use cannabis, while 28-40 percent in Denmark, France, Ireland, the Netherlands, Spain, and the United Kingdom; amphetamines, ecstasy and cocaine $1-6 \%$ (in the UK these numbers are higher - 16\% (amphetamine) and 8\% (ecstasy) [10].

Although in some external parameters our internal situation is similar to that in some Western countries (e.g., with general features of scale), their internal mechanisms are almost identical. Nevertheless, it would be illogical to formulate a strategy without considering the existing ones. Moreover, even within a single society, as a rule, not one, but several additional strategies (models) are implemented.
For example, there are currently at least three models of drug prevention in the United States. The most popular of these is the "demand and supply model," which focuses on reducing demand and supply in parallel with medicines. Another model from the American National Institute on Drug Abuse (NIDA) found that addiction is a problem for a person, 1) low level of awareness, 2) education, 3) potential 4) is determined by prevention programs.

The third model, proposed by the National Institute for the Study of Alcohol and Alcohol Abuse (NIAAA), is based on a public health prevention strategy that implements three areas: the individual himself, sources of threat, and the external environment [11].

In our view, the external simplicity of the proposed scheme does not imply the practical simplicity of solving the drug problem. It is well known that any social process or task can be accomplished only when there is a relatively strong social stratum or group in society that is objectively interested in it. However, according to their functional status, the vast majority of those who participate in various anti-drug campaigns and programs are not interested in being distracted by the temptations of addiction, except for all drug users.

In other countries and at other times, researchers have already noted that "if different departments develop conflicting programs, they are more likely to conflict with each other, and moreover, the efforts of one department may face strong opposition from others" [12].

According to data published in the World Drug Report (2013), 211,000 drug-related deaths worldwide were reported in 2011, mainly due to opioids, using estimates by international experts. Most of the dead were young drug users. The results of the analysis of irreversible losses as a result of drug, psychotropic and 
sedative consumption in the Russian Federation show that $2 / 3$ of the causes of death are related to drug overdose. In turn, half of the deaths of women from psychotropic substances were suicidal [13].

When it comes to assessing deaths related to drug and psychotropic substance use, it should be borne in mind that there is no single methodological approach to data collection, so deaths are very high in the World Drug Report.

According to data published in the World Report on Drugs (2012), it is the most common type of illicit drug, and in 2009 there were 125 to 203 million people worldwide. This corresponds to an annual consumption rate of 2.8-4.5 percent of the population aged 15 to 64 years. These figures are highest in Oceania (9.3\% to $14.8 \%$ ), North and South America (6.3\% to $6.6 \%$ ), and some regions of Western Europe reduce cannabis use. However, there is evidence of an increase in cannabis consumption in the South American population, whose annual prevalence is lower than in North America. The lack of scientifically based reliable data on cannabis use on these continents in Africa and Asia is indicative of negative trends in cannabis use.

In North America, the prevalence of dangerous behaviors among adolescents related to marijuana smoking and alcohol consumption has been steadily increasing since the 1980s [14]. Most American teens consume more alcohol than other substances [15].

While drug use has become illegal in almost all countries, this fact is not related to the proliferation of adolescents who see cannabis as part of their normal behavior and peer group culture. There are major differences in drug and drug policy in the European region and North America. Government policies (health education, health promotion, and counseling programs at schools, families, and local communities) should increase cannabis consumption and make the majority of young people addicted. Same with other culturally legitimate psychoactive substances as alcohol [16].

Globally, ATs (amphetamine-type stimulants) rank second in the country in terms of annual statistics on the annual prevalence of cannabis drug use. The number of users of amphetamine-type stimulants (ATs) exceeded the number of opiate and cocaine users, ranking third and fourth, respectively. With the exception of ecstasy, ATs consumption tends to increase in many regions, based on widespread and published data around the world. According to the country's 2011 data, about 0.7 percent of the world's population aged 15-64, or 33.8 million people, used ATS last year. In 2011, ecstasy consumption decreased compared to 2009 (19.4 million people or $0.4 \%$ of the population).

A distinctive feature of ATs market valuation is its mobility, the ways in which ATs are illegally distributed are very short, and the production of ATs is carried out close to major consumer markets, and most of the raw materials used are legal. Manufacturers of illicit businesses are offering new drugs (e.g., compounds that smoke ketamine, mephedrone, and spices) into circulation and entering new markets. The most important group of ATs are "amphetamines" [17].

Consumption of ecstasy is becoming increasingly important. Illegal "ecstasy" products are spreading to countries covering almost all regions of the world. In Europe and other markets, synthetic psychotropic substances are increasingly appearing, which are sold in tablets under the guise of "ecstasy". The popularity of "club" drugs has grown - piperazine, ketamine and other surrogates sold under the guise of "ecstasy" or under their own names. In response to this change in demand, drug production sites have changed. In the past, most of the pills sold 
under the guise of "ecstasy" were made in Europe, but this is no longer the case. Ecstasy production has increased in North America (especially Canada) and parts of Asia.

Opioids are the third most prevalent in the world. Experts estimate that 24-35 million people worldwide use these substances, which is $0.5-0.8$ percent of the population aged 15-64. The most problematic opioids in the world are opiates, i.e. various psychoactive substances derived from the opium poppy plant, primarily opium and heroin. The most problematic opium drug in the world is heroin [18].

According to statistics, in 2019, there were about 12-14 million heroin users worldwide. The Russian Federation and Western Europe are the largest global markets for Afghan opium. Together, they consume almost half of the heroin produced in the world. It is estimated that in 2018, 340 tons of heroin were consumed worldwide. The second largest heroin market: the Russian Federation. Every year, 25 percent of all Afghan heroin (95 tons) is transported from Afghanistan to Central Asia via the northern route to meet demand in the Russian Federation, which is 70 tons. The number of drug users in Russia, according to expert estimates published in the World Report. on drugs (2011), 1.6-1.8 million people. Thus, the prevalence rate of the population aged 15 to 64 years is $1.6 \%$. According to some reports, heroin consumption in Europe is declining due to a number of factors, including the aging of drug users and the suppression of illicit heroin supply. However, there are reports of nonmedical use of prescription opioid drugs in some parts of Europe.

Cocaine is the fourth most common drug in the world. It is estimated that 14 to 21 million people used it in 2009, which corresponds to a prevalence of $0.3-0.5 \%$ of the population aged 15-64 years.

\section{RESULT AND DISCUSSION}

Cocaine has long been considered a drug for the rich, now it has become a drug for the general population. From 2006 to 2011. The U.S. has seen a long-term decline in demand for cocaine. In the United States, cocaine use fell by $40 \%$ among the general population, partly due to declining production in Colombia, and the brutal struggles of law enforcement and the cartel.

Unlike the United States, the number of cocaine users in Europe has doubled in the last decade, from 2 million in 1998 to 4.1 million. In 2008 in the European Union and EFTA countries. The UK is the largest national market for cocaine in Europe, followed by Spain, Italy, Germany and France. Cocaine consumption in Europe in 2008 was estimated at 124 tons [19].

The analysis shows that, in general, the total number of users of the above-mentioned drugs did not change significantly, and the recorded changes are in the existing range. $A$ wide range of experts around the world, from "significant decline" to "significant growth," reported that drug use stabilized in 2009. These include cannabis, amphetamines, ecstasy, narcotics, and narcotics [20].

The analysis showed that the production of illicit drugs in Europe is mainly related to cannabis, amphetamines and ecstasy. In 2008, 29 European countries reported growing cannabis at home. Most of the amphetamines seized in Europe were produced in the Netherlands, Poland and Belgium. The clandestine production of methamphetamine is concentrated in the Czech Republic, but some volumes are also produced in the Baltic countries. But the production and consumption of methamphetamine in Europe is an exception. Cocaine seizures remain concentrated in Western Europe. Western and Central European countries accounted for $97 \%$ of cocaine seizures in Europe in 2009. In 2009, 
Europe accounted for $38 \%$ of global heroin seizures. The majority of heroin seizures were concentrated in Southeast Europe (63\% of all heroin seizures in Europe), while heroin seizures in Western and Central Europe remained almost stable from 2005 to 2009; In Southeast Europe it has doubled [21].

Europe is mainly the last use for heroin. The exception is ecstasy, which is still locally produced and then shipped to other destinations. The share of global ecstasy eclipses in Europe decreased from 90\% in 1996 to $18 \%$ in 2009. In 2009, Europe accounted for $24 \%$ of amphetamine seizures. Between 2005 and 2009, seizures of benzodiazepines and barbiturates increased by $50 \%$, while almost 90\% of global seizures occurred in European countries [22].

In line with the purpose of the study, it is important for us to analyze the use of synthetic drugs and medications. It should be noted that, unlike in other regions of the world, the non-medical use of prescription drugs in Europe is still not considered a serious problem. In Denmark, Estonia and Finland, prescription opioid consumption for medical unhealthy purposes is very high, which is higher than heroin consumption. Northern Ireland (United Kingdom) has reported the highest rates of non-medical prescription opioid consumption to date. Northern countries, Sweden (11.6\%), Norway (10.2\%) and Finland (8.5\%) accounted for the largest share of the use of sedatives and tranquilizers). The use of benzodiazepines is widespread in Europe among drug users, including those engaged in substitution therapy. Studies show that $11 \%$ to $70 \%$ of those experiencing this therapy report current use of benzodiazepines.

The increase in the abuse of large amounts of narcotic drugs, especially the concomitant use of prescription drugs in combination with illicit substances, including the misuse of sedatives and tranquilizers, is a cause for concern. This situation is typical of many countries around the world where an increase in the consumption of synthetic drugs and prescription drugs, including synthetic opioids, benzodiazepines, has been observed. According to international experts and Russian researchers, the use of prescription drugs for non-medical purposes is becoming a growing problem in the health sector [23].

In addition, in recent years, new synthetic substances have played an increasingly important role in the composition of illicit drugs. This has led to the rapid growth of production and distribution of new psychoactive substances, the complexity of response measures and the fight against them in the international drug control system. From 2009 to 2012, their number increased by more than $50 \%$. For the first time, the number of drugs exceeded the total amount of substances under international control.

NPS are substances that are abused both in pure form and in drug form and are not regulated under international drug conventions. In general, the term NPS is a general term for products designed to have similar effects to unregulated (new) psychoactive substances or controlled drugs.

Many NPS are marketed as "legitimate tone stimulants" and replace illicit stimulants such as cocaine or "ecstasy". Examples include internationally uncontrolled piperazines and mephedrone. Similar changes are observed for cannabis, especially as the demand for synthetic cannabinoids has increased in some countries. SPICE sold on the Internet and in specialty stores is used as a "legal alternative" to cannabis and is not subject to international control.

In 2010, more than 40 new substances were registered. These include piperazines, cathinones, synthetic cannabinoids, tryptamines, and phenytolamines, piperazines. Piperazine was originally 
developed as an anthelmintic to treat parasitic worms. The most well-known piperazine derivative, benzylpiperazine (BZP), was later developed as an antidepressant but did not enter the market because it had a $d$ amphetamine-like effect but was less potent. BZP, like amphetamines, promotes euphoria and has stimulant properties. Piperazine derivatives such as BZP and 3trifluoromethylpiperazine (TFMPP) are often marketed under the name 'ecstasy'.

Mefedron, also known as 4methylmethcatinone (4-MMK), is chemically bound to syncoactive cathinone, which is internationally controlled and found in plant cats along with other psychoactive substances. Mephedrone, a commonly reported drug from Europe, North America, and Australia, recently entered the drug market. It is often offered as a legal alternative to amphetamines or cocaine. Although mephedrone and its analogues, such as nafiron, have similar effects to internationally controlled substances, their production and distribution are often not restricted by law due to differences in chemical composition.

\section{CONCLUSION}

The diversity of the cannabis market has been helped by the emergence of synthetic cannabinoids that mimic the effects of cannabis consumption. Since 2008, synthetic cannabinoids - "plants" - have been found in plant cigarette mixtures. Typically, these mixtures contain about 3 grams of finely chopped plant material to which one or more synthetic cannabinoids are added. Because these compounds do not contain internationally controlled ingredients, they are often referred to as a "legal alternative" to cannabis. Almost nothing is known about the new pharmacological and toxicological properties when combined, but these substances add a stronger like cannabis. As part of the fight against drugs, a number of countries have taken control of spices and similar products, which has exacerbated the problem. A completely new phenomenon in the pharmaceutical market is the dilution of cocaine with various solvents, such as lactose or active compounds such as atropine, phenacetin and methylphenidate. The presence of such compounds can enhance the desired effects of medications and even reduce or eliminate some of the negative effects of drug use. The Netherlands, as well as a number of other countries in Europe and North America, have reported an increase in the number of cocaine samples mixed with levamisole, an anthelmintic agent for the treatment of nematodes, in 2008 and 2009, respectively.

The International Report on Drugs (Crocodile) Worldwide (2018) notes that in a number of countries where there is no money to buy heroin, which is also known as desomorphine by poor people, are increasingly being used. Injecting this substance, even in small amounts, can lead to serious health and even death.

\section{REFERENCES}

1. World Drug Report 2012. https://www.unodc.org/data-andanalysis/WDR2012/WDR_2012_Russian _web.pdf

2. 2. Drug threat and counteraction, 2000; International legal framework for combating drug trafficking, 2005).

3. Reuter, P. Ten years after the United Nations General Assembly Special Session (UNGASS): assessing drug problems, policies and reform proposals. Addiction 2009; 104:510-7.

4. Drug Trafficking: Global Trends and Challenges, 2007. http://cadapeu.org/upload/file/publications/situatio n_reports/01_AR\%202012_Uzbekistan_ UZB_final_www.pdf 
5. EMCDDA. Guidelines for Estimating the Incidence of Problem Drug Use. 2008; Lemstra M., 2009; E. Freisthler, P.J.Gruenewald, 2014.

6. Lea, 2014; R.T. Mikolajczyketal., 2014

7. T.J.Dishion, L. Loeber, 1985; Pandina R., 1990; R. Kosterman, J.D.Hawkins, J. Guo, R.F. Catalano, R.D.Abbott, 2000; E.M. Ossiander, 2015

8. Johnston, L.D., O'Malley, P.M. \&Bachman, J.G. National Surveyresults on drug use from the Monitoring the Future Study, 1975-1997.

9. Ann Arbor, MI: Institute for Social Research, 1998, p.94; www.monitoringthefuture.org.

10. Johnston, L.D., O'Malley, P.M. \&Bachman, J.G. National Survey results on drug use from the Monitoring the Future Study, 19751997.

11. C.J. Connors, A.R. Tartox, 1985; B. Hibell, 2000; J.B. Janin, 2001; Hibell B. 2000; The health of young people and their environment. 2007; Degenhardt L., 2010; Nilsson M., 2010; I. Lander, 2015.

12. Shabalina V.V. Psychology of addictive behavior. - SPb .: Publishing house of St. Petersburg. University, 2004, p. 177.

13. Grant M. \& Ritson B. Alcohol: The prevention debate. New York: St.Martin's Press, 1983. Цит. по: Шабалина В.В. Зависимое поведение школьников. - СПб: Медицинская пресса, 2001, с. 39.

14. Abramov A.Yu., Mikhailov A.Yu., Semenova V.G., Nikitina S.Yu., Sabgaida T.P., Gavrilova N.S., 2014.

15. Poulin C, Elliot D., 1997; J. Bachman, 1998; J.M. Rey, M.G. Sawyer, B. Raphael, G.C. Patton, M. Lynskey, 2002; King A., 2000; R. Kosterman, J.D.Hawkins, J. Guo, R.F. Catalano, R.D.Abbott, 2000; Licanin I., 2005; Schepis T.S., 2008; Swift W., 2008; M.Lemstra, C.Neudorf, 2009;
Schuermeyer J., etal., 2014; A.-K Danielssonetal., 2015

16. R. Kosterman, J.D.Hawkins, J. Guo, R.F. Catalano, R.D.Abbott, 2000; M.Lemstra, C.Neudorf, 2009; Schmid H., 2001

17. The health of young people and their environment. WHO / Europe, 2007; Brook J. 1999; L. Degenhardt, C. Coffey, J.B. Carlin, W. Swift, E. Moore, G.C. Patton, 2010

18. World Drug Report. 2019 https://www.unodc.org/unodc/ru/fron tpage/2019/June/world-drug-report2019

19. M. Ferri, M. Davoli, C.A. Perucci, 2011; Саидмурадов Д. У., 2014; А.C.Meyer, 2014

20. Dany, L, Apostolidis, T. L'étudedes représentations social esdeladrogueetducannabis:

unenjeupourla prévention // Santé publique, 2002. - vol.14, №4.

21. World Drug Report. 2011. https://www.unodc.org/documents/w dr2014/WDR_Russian.pdf

22. EMCDDA. 2018. Annual report: the state of the drugs problems in Europe. 2018.

23. EMCDDA. 2019. Annual report: the state of the drugs problems in Europe. 2019.

24. Nikolaeva N.M., 2005, 2011; Movsesyan L.O., 2010; Feklin S.I., 2011; World Drug Report 2012 